\title{
A NOVEL SIMULTANEOUS STABILITY-INDICATING UPLC ASSAY METHOD FOR METFORMIN HYDROCHLORIDE AND CANAGLIFLOZIN IN ORAL SOLID DOSAGE FORM
}

\author{
Vijay Kumar Rekulapally1 ${ }^{*}$, Sripal Reddy Palavai2, Raghunadha Reddy Seelam³ \\ ${ }^{1}$ Dr. Reddy's Laboratories Ltd. IPDO, Bachupally, Hyderabad, Telengana, 500090. \\ ${ }^{2}$ Aurobindo Pharma USA,INC, Raleigh , North Carolina, USA - 27606. \\ 3Department of Pharmaceutical Sciences, University of Maryland, School of Pharmacy, Baltimore, \\ MD, United States \\ Corresponding author E- mail: vijaykmpharm@gmail.com
}

Received: 28 January 2018

Revised: 12 February 2018

Accepted: 24 February 2018

\begin{abstract}
:
A Novel, Simultaneous stability indicating RP-HPLC method was developed for combined estimation of Metformin Hydrochloride (CANA) and Canagliflozin (MET) in fixed dose pharmaceutical formulations. The developed chromatographic method for the separations of CANA and MET and its degradation products by the use of stationary phase BEH C18 column, $50 \times 2.1 \mathrm{~mm}, 1.7 \mu \mathrm{m}$ column with mobile phase consisting of sodium dihydrogen phosphate buffer (30 mM) and $10 \mathrm{mM}$ of 1-Octane Sulphonic acid in $1000 \mathrm{ml}$ of water in mobile phase A, mobile phase B mixture of Methanol: Acetonitrile 50:50 v/v ratio at a flow rate of $0.3 \mathrm{~mL} / \mathrm{min}$, with reproducible gradient program. Chromatographic separations was made of analytical peaks and degradation peaks occurring within 10 min. Detection of the analytes - Metformin at $230 \mathrm{~nm} \&$ Canagliflozin at $290 \mathrm{~nm}$ using PDA detector. Method validation was performed as per ICH guidelines. Linearity of the method was established from 2-170 $\mu \mathrm{g} / \mathrm{ml}$ for Metformin hydrochloride and 12$180 \mu \mathrm{g} / \mathrm{ml}$ for Canagliflozin ( $\left.\mathrm{R}^{2} 0.999\right)$. The method can be considered as stability-indicating and can be used for simultaneous determination of CANA and MET in fixed dose pharmaceutical formulations and drug product stability studies.
\end{abstract}

Keywords: UPLC; Metformin; Canagliflozin; Stability indicating, Stress induced degradation products; ICH guidelines

\section{INTRODUCTION}

Metformin hydrochloride is chemically designated as 1,1-Dimethylbiguanide hydrochloride (Fig. 1A). It is used in the treatment of type 2 diabetes[1]. Canagliflozin
(Fig. 1B) chemically designated as $(2 \mathrm{~S}, 3 \mathrm{R}, 4 \mathrm{R}$, 5S, 6R)-2-\{3-[5-[4-Fluoro-phenyl)-thiophen2-ylmethyl]-4-methyl-phenyl\}-6-

hydroxymethyl-tetrahydro-pyran-3,4,5-triol. 
It is used to treat type 2 diabetes ${ }^{[2-6]}$. Both CANA and MET been analyzed by various techniques either alone or in combination with other drugs. Analytical methods existed for Metformin hydrochloride included determination by HPLC[7] and UPLC[8]. Analytical methods existing for Canagliflozin included determination by high performance liquid chromatography[9-10], and CANA and MET combination analyzed by using HPLC[1112]. The combination of CANA and MET has not been discussed any official

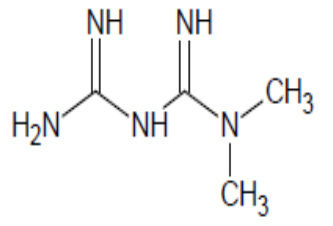

(A) pharmacopoeia like USP, BP or EP, etc. There not been any literature found for drug substance and drug product stability indicating UPLC method (with or without forced degradation studies) for simultaneous determination of both drugs. Hence tried and succeeded to develop and validate ${ }^{[13-16]}$ a simultaneous simple, precise, and sensitive, stability indicating UPLC method for the combined determination of CANA and MET in drug product.

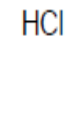

Fig. 1 Chemical structure of Metformin $\mathrm{HCl}$ (A), Canagliflozin (B)

\section{MATERIAL AND METHODS}

\subsection{Chemicals and reagents}

Canagliflozin hydrochloride, Metformin hydrochloride standard were supplied by Dr. Reddy's Laboratories (Hyderabad, India). The UPLC-grade Acetonitrile analytical grade, $\mathrm{NaH}_{2} \mathrm{PO}_{4}$ monohydrate and Ortho-phosphoric acid were sourced from Merck (Darmstadt, Germany). Water was sourced from Millipore MilliQ.

\subsection{Equipments}

Analysis was performed with a Waters (Milford, MA) Acuity UPLC system equipped with a quaternary solvent manager, sample manager, column-heating compartment and photodiode array detector. This system was controlled by Waters Empower3 software. An Acquity UPLC BEH C18 column, 50×2.1 $\mathrm{mm}, 1.7 \mu \mathrm{m}$ (Waters) was employed for chromatographic separation. Thermo Scientific multifuge centrifuge machine, heating oven (MACK Pharmatech, Hyderabad, India), photo stability chamber, water baths and Milli Volt controller (Julabo, Seelbach, Germany) were used for hydrolysis studies. 


\subsection{Chromatographic conditions}

The column used was UPLC BEH C18 column, $50 \times 2.1 \mathrm{~mm}, 1.7 \mu \mathrm{m}$ as stationary phase. The mobile phase A buffer was prepared by dissolving $4.15 \mathrm{~g}$ of Sodium dihydrogen phosphate and 1.0g of 1-Octane sulphonic acid in $1000 \mathrm{ml}$ of water, filtered through $0.22 \mu$ filters and mobile phase $B$ was constituted as a mixture of Methanol: Acetonitrile 50:50 v/v ratio. A mixture of Milli Q water and Acetonitrile in 50:50 v/v was used as a diluent to prepare solutions. The gradient program Time (minutes)/\% mobile phase $A$ was set as $0 / 100,8 / 0,8.1 / 100$, $10 / 100$ respectively. Before use, the mobile phase was mixed thoroughly and degassed. The mobile phase was pumped at $0.3 \mathrm{ml} / \mathrm{min}$. The eluted compound CANA and its impurities monitored at $230 \mathrm{~nm}$, MET and its impurities were monitored at $290 \mathrm{~nm}$. The column used at $25^{\circ} \mathrm{C}$ temperature. The injection volume for samples and standards set as $0.4 \mu \mathrm{L}$.

\subsection{Preparation of standard stock solution} of CANA
Accurately $60 \mathrm{mg}$ of CANA working standard was weighed into a $50 \mathrm{ml}$ volumetric flask, dissolved in diluent and made up to volume with diluent and mixed well.

\subsection{Preparation of standard stock solution of MET}

Accurately $50 \mathrm{mg}$ of MET working standard was weighed into a $50 \mathrm{ml}$ volumetric flask, dissolved in and diluted to volume with diluent and mixed.

\subsubsection{Preparation of standard olution of CANA\& MET}

Accurately $5 \mathrm{ml}$ each of CANA and MET standard stock solutions were pippetted into a $100 \mathrm{ml}$ volumetric flask, dissolved in diluent and made up to volume with diluent and mixed well.

\subsection{Preparation of sample solution}

Sample stocks were made up to 3000 $\mu \mathrm{g} / \mathrm{ml}$ of CANA and $20000 \mu \mathrm{g} / \mathrm{ml}$ of MET by using diluent, and they were further diluted to achieve final concentrations of $12 \mu \mathrm{g} / \mathrm{ml}$ of CANA and $80 \mu \mathrm{g}$ of MET with diluent. The solution was filtered through $0.45 \mu$ nylon filter. 


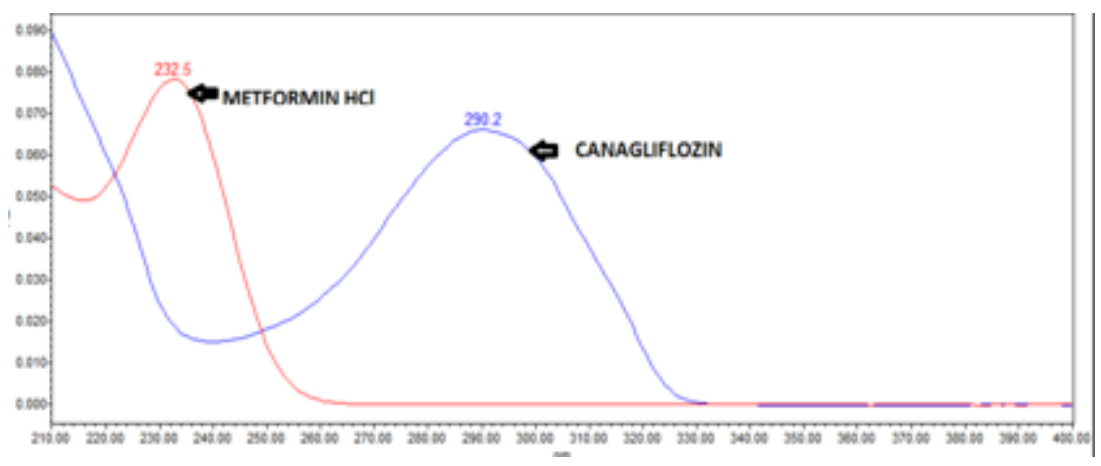

Fig. 2 Finalization of Chromatographic conditions

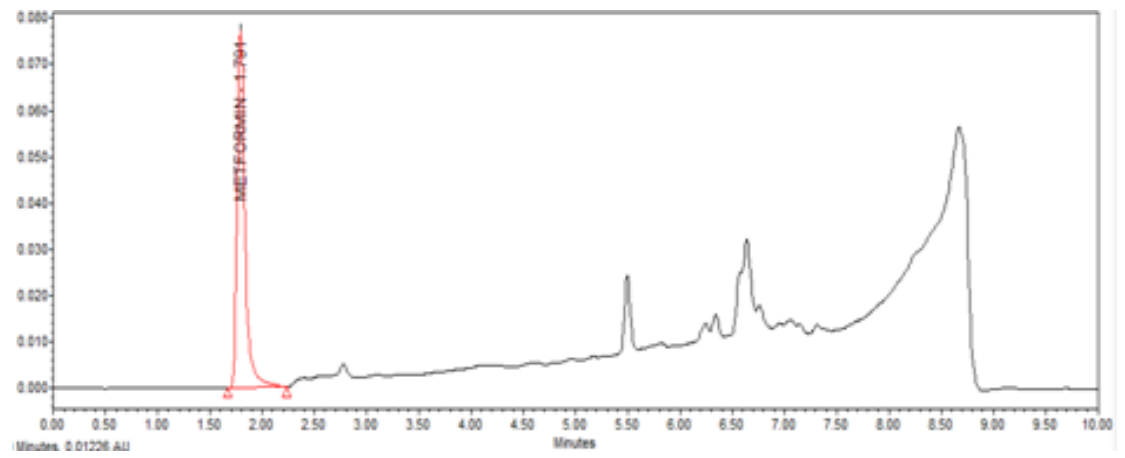

Fig. 3 Finalized standard chromatogram of MET at $230 \mathrm{~nm}$

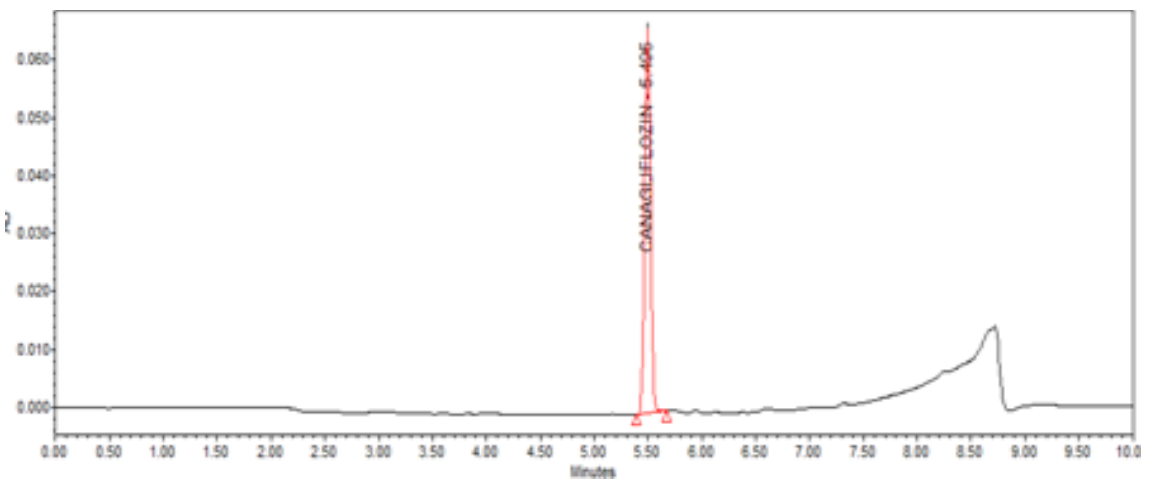

Fig. 4 Final standard chromatogram of CANA at $290 \mathrm{~nm}$

\subsection{Precision}

Performed six sample preparations on the same day and inter-day, the \%RSD of the peak area were then calculated to represent precision.

\subsection{Linearity}

Linearity obtained over concentration ranges of $12 \mu \mathrm{g}$ to $180 \mu \mathrm{g}$ for CANA and $2 \mu \mathrm{g}$ to 170 $\mu \mathrm{g}$ for MET. Each solution was prepared in triplicate.

\subsection{Accuracy}

Accuracy of developed method was determined by spiking API on placebo various concentrations ranging from 50\% of lower strength $(50 \mathrm{mg}$ for CANA and $500 \mathrm{mg}$ for MET) to $150 \%$ of higher strength (150 mg for 
CANA and $1000 \mathrm{mg}$ for MET) of target test concentration. Six preparations were lower and higher concentration for covering the data in the range and for remaining levels in triplicate preparations.

\subsection{ROBUSTNESS}

Robustness was performed with $10 \%$ organic variation in mobile phase composition, 0.02 $\mathrm{ml} / \mathrm{min}$ flow rate. The changes in retention time, tailing factor and number of theoretical plates were studied.

\subsection{Limit of detection (LOD) and limit of quantification (LOQ)}

Detection and quantification limits were determined by the signal-to-noise $(\mathrm{S} / \mathrm{N})$ approach. In order to examine the LOQ and LOD solutions of dissimilar concentrations were prepared by spiking known amounts of CANA and MET spiked in diluent. The average $\mathrm{S} / \mathrm{N}$ ratio from all the analyses at each concentration level was used to calculate the LOQ and LOD. The concentration which gives more than 10 readily quantified. The concentration at which gives $\mathrm{S} / \mathrm{N}$ ratio 3 can be readily detected was reported as the LOD.

\subsection{Specificity}

A study was conducted to demonstrate the effective separation of degradents from CANA peak MET peak and by forced degradation studies of CANA and MET tablets.

\subsubsection{Acid degradation studies}

Acid stress was induced by subjecting to $1 \mathrm{M}$ $\mathrm{HCl}$ at $60{ }^{\circ} \mathrm{C}$ for $24 \mathrm{~h}$ and keeping on a shaking water bath. After administration of the stress the solution was neutralized with $1 \mathrm{M} \mathrm{NaOH}$, and a further sample was prepared with diluent.

\subsubsection{Base degradation studies}

Base stress was simulated by using $1 \mathrm{M} \mathrm{NaOH}$ at $60^{\circ} \mathrm{C}$ for $3 \mathrm{~h}$ and keeping on a shaking water bath. After induction of the stress the solution was neutralized with $1 \mathrm{M} \mathrm{HCl}$, further sample was prepared with diluent.

\subsubsection{Oxidative degradation studies}

Oxidative stress was performed by using 30\% $\mathrm{H}_{2} \mathrm{O}_{2}$ for $24 \mathrm{~h}$ in room condition. After completion of the stress, further sample prepared with diluent.

\subsubsection{Thermal degradation studies}

Thermal degradation was performed at $105^{\circ} \mathrm{C}$ for $24 \mathrm{~h}$. After completion of the stress, further sample preparation was made as a control sample.

\subsubsection{Photolytic degradation studies}

For photolytic degradation study performed in photolytic chamber (1.2 million lux per hour and 200 watt hour/square meter) for 16 h. After completion of the stress on sample same samples used for the sample preparation.

\section{RESULTS AND DISCUSSION}

Liquid chromatographic analysis of Metformin and related impurities showed that they were highly polar, with low UV absorbance. CANA was moderately polar, 
with potential degradation impurities. These challenges were considered for simultaneous method development.

Preliminary studies involved trying different stationary phases and testing several mobile phase compositions for the effective separation of CANA and MET. Both analytes have different retention behaviors; hence it was challenging to separate both analytes in shorter method without interfering placebo components and degradation impurities. Method development started with evaluating retention of CANA \& MET and in reversedstationary phases (C8, and C18 columns), Phosphate buffer with organic modifiers, by keeping MET retention as a target. Further chromatographic elutions were optimized by using an ion pair reagent which helped to retain MET, but the CANA peaks were not symmetrical, In order to improve the CANA peak symmetry chromatographic parameters The method was validated as per ICH guidelines (ICH 1996), Q2(R1). Evaluated validation parameters were linearity, accuracy, precision, robustness, specificity, limit of detection and quantitation.

\subsection{Validation}

Linear curve plotted in concentration ranges of $13-181 \mu \mathrm{g} / \mathrm{ml}(13,32,65,103,129$ and $181 \mu \mathrm{g} / \mathrm{ml}$ ) for MET and 12-170 $\mu \mathrm{g} / \mathrm{ml}$, CANA $(12,30,60,96,120$ and $170 \mu \mathrm{g} / \mathrm{ml})$. The linear regression equation for MET was found were evaluated using a combination of phosphate buffer and ion pair agent and commercially available stationary phases like BEH Shield C8 and HSS T3 column, BEH C18 with linear gradient programs. Finally the best separation was observed with sodium dihydrogen phosphate monohydrate and 1octane Sulphonic acid monohydrate buffer, stationary phase BEH C18, $50 \mathrm{~mm} \times 2.1 \mathrm{~mm}$, $1.7 \mathrm{~m}$ column linear gradient program. MET $\lambda_{\max }$ was at $230 \mathrm{~nm}, \mathrm{CANA} \lambda_{\max }$ was at $290 \mathrm{~nm}$. Measuring both compounds at a specified wavelength was not possible due to the difference in the UV absorbance characteristics.

Symmetrical and high intensity peaks of CANA and MET chromatograms were recorded in above chromatographic conditions, the retention time of Metformin and Canagliflozin were $1.77 \mathrm{~min}, 5.42 \mathrm{~min}$, respectively, System suitability data are summarized in Table 1.

to be $\mathrm{Y}=3815 \mathrm{X}+36.3$ with correlation coefficient greater than 0.999 . The linear regression equation for CANA was found to be $\mathrm{Y}=7450 \mathrm{X}+5367$ with correlation coefficient greater than 0.999 . The limit of detection (LOD) and quantification (LOQ) were determined by making serial dilutions. LOD was found to be $0.165 \mu \mathrm{g}$ and $0.122 \mu \mathrm{g}$ for CANA and MET, respectively (signal to noise ratio of $3: 1$ ). LOQ was found to be $0.504 \mu \mathrm{g}$ and $0.65 \mu \mathrm{g}$ for CANA and MET, respectively 
(signal to noise ratio of 10:1). Accuracy performed on three levels 50\%, 100\% and $150 \%$ and its percentage recoveries along with standard deviation and relative standard deviations for each analytes are given in table 3. Recovery studies showed the method to be highly accurate and suitable for intended use. Intra-day precision was determined by injecting six sample solutions of target concentrations on the same day and inter-day precision was determined by injecting the same solutions for three consecutive days. Relative standard deviation (\%RSD) of the peak area was calculated to represent precision. Results of intra-day and inter-day precision are presented in Table 2. Robustness of the method was performed by slightly varying chromatographic conditions. The results showed that slight variations in chromatographic conditions had a negligible effect on the chromatographic parameters (Tables 5 and 6). Specificity of the developed method was evaluated by applying different stress conditions (acid, base, oxidation, thermal and photolytic) to CANA and MET in combination form.

Table 1: System suitability parameters of CANA and MET

\begin{tabular}{cccc}
\hline Component & Retention time & Tailing factor & Theoretical plates \\
\hline MET & 1.7 & 1.4 & 3423 \\
CANA & 5.4 & 1.1 & 47935 \\
\hline
\end{tabular}

Table 2: Intra-day and inter-day precision of the proposed UPLC method.

\begin{tabular}{ccccc}
\hline & Intra-day precision measured & \multicolumn{2}{c}{ Inter-day precision measured } \\
\hline S.No & MET & CANA & MET & CANA \\
\hline 1 & 98.2 & 98.6 & 98.6 & 98.5 \\
2 & 98 & 99.1 & 98.3 & 98.1 \\
3 & 98.7 & 98.4 & 99.3 & 99.7 \\
4 & 99.3 & 98.0 & 99.7 & 99.2 \\
5 & 98.2 & 99.5 & 98.6 & 98.7 \\
6 & 99.2 & 98.8 & 99.2 & 98.5 \\
\hline Avg & 98.6 & 98.7 & 99 & 98.8 \\
\%RSD & 0.6 & 0.5 & 0.5 & 1.5 \\
\hline
\end{tabular}


Table 3: Accuracy of the proposed UPLC method.

\begin{tabular}{|c|c|c|c|}
\hline Drugs & $\begin{array}{c}\text { Spiked } \\
\text { concentration in mg }\end{array}$ & $\begin{array}{c}\text { Synthetic mixtures } \\
\text { measured } \\
\text { concentration (mg) } \pm \\
\text { SD; RSD (\%) }\end{array}$ & $\begin{array}{c}\text { Synthetic mixtures measured } \\
\text { concentration (\%Recovery) } \\
\pm \text { SD; RSD (\%) }\end{array}$ \\
\hline \multirow[t]{3}{*}{ Metformin } & 3500 & $3466.2 \pm 37.9,1.1$ & $99.0 \pm 1.0,1.1$ \\
\hline & 10000 & $9873.3 \pm 61.6,0.6$ & $98.7 \pm 0.6,0.6$ \\
\hline & 15000 & $14960 \pm 99.9,0.7$ & $99.7 \pm 0.7,0.6$ \\
\hline \multirow[t]{3}{*}{ Canagliflozin } & 350 & $346.3 \pm 3.9,1.1$ & $99.0 \pm 1.5,1.5$ \\
\hline & 1500 & $1518.9 \pm 17.5,1.2$ & $100.9 \pm 1.2,1.1$ \\
\hline & 2250 & $2228.3 \pm 9.4,0.4$ & $99.0 \pm 0.4,0.4$ \\
\hline
\end{tabular}

Table 4: Stress testing results of CANA and MET

\begin{tabular}{ccccc}
\hline $\begin{array}{c}\text { Nature of } \\
\text { stress }\end{array}$ & Storage conditions & $\begin{array}{c}\text { Time } \\
(\mathrm{h})\end{array}$ & $\begin{array}{c}\text { MET } \\
\text { remaining }\end{array}$ & $\begin{array}{c}\text { CANA } \\
\text { remaining }\end{array}$ \\
\hline $1 \mathrm{M} \mathrm{HCl}$ & $60 \mathrm{C}$ & 24 & 98.7 & 99.1 \\
$1 \mathrm{M} \mathrm{NaOH}$ & $60^{\circ} \mathrm{C}$ & 3 & 96.8 & 98.3 \\
$30 \% \mathrm{H}_{2} \mathrm{O}_{2}$ & $\mathrm{Room} \mathrm{Temp}$ & 24 & 98 & 93.6 \\
Thermal & $105^{\circ} \mathrm{C}$ & 24 & 99.4 & 95.2 \\
Photolysis & Photolytic chamber & 18 & 100.6 & 100.4 \\
\hline
\end{tabular}

Table 5: Robustness study of Metformin

\begin{tabular}{crccc}
\hline Chromatographic conditions & Assay & tR(min) & Theoretical plates & Tailing \\
\hline Buffer: Methanol(780:220) & 98.5 & 1.5 & 4125 & 1.3 \\
Buffer: Methanol(800:200) & 99.7 & 1.7 & 3418 & 1.4 \\
Buffer: Methanol(820:180) & 98.2 & 1.9 & 3652 & 1.4 \\
Flow rate (0.32 mL/min) & 98.6 & 1.9 & 3982 & 1.5 \\
Flow rate (0.3 mL/min) & 99.7 & 1.7 & 3418 & 1.4 \\
Flow rate (0.28 mL/min) & 98.5 & 1.4 & 3325 & 1.3 \\
Acetonitrile: Methanol(480:520) & 99.2 & 1.6 & 3865 & 1.5 \\
Acetonitrile: Methanol(500:500) & 99.7 & 1.7 & 3418 & 1.4 \\
Acetonitrile: Methanol(520:480) & 98.6 & 1.5 & 3125 & 1.4 \\
\hline
\end{tabular}


Table 6: Robustness study of Canagliflozin

\begin{tabular}{ccccc}
\hline Chromatographic conditions & Assay & tR(min) & Theoretical plates & Tailing \\
\hline Buffer: Methanol(780:220) & 99.2 & 5.1 & 46852 & 1.2 \\
Buffer: Methanol(800:200) & 98.6 & 5.4 & 47853 & 1.1 \\
Buffer: Methanol(820:180) & 98.5 & 5.9 & 51264 & 1.1 \\
Flow rate (0.32 ml/min) & 98.7 & 5.7 & 45158 & 1.3 \\
Flow rate (0.3 ml/min) & 98.6 & 5.4 & 47853 & 1.1 \\
Flow rate (0.28 ml/min) & 99.2 & 5.2 & 42153 & 1.1 \\
Acetonitrile: Methanol(480:520) & 98.7 & 5.3 & 48521 & 1.2 \\
Acetonitrile: Methanol(500:500) & 98.6 & 5.4 & 47853 & 1.1 \\
Acetonitrile: Methanol(520:480) & 98.5 & 4.9 & 48532 & 1.2 \\
\hline
\end{tabular}

\subsection{Force degradation study}

The chromatograms under acidic, basic, peroxide, thermal and photolytic stress conditions are shown in Figures. 5 to 9 for both the active ingredients. The results of stress studies are given in Table 4. All the stress conditions applied were enough to degrade both the drugs. Comparison of the two drugs showed that MET is more stable as compared to CANA. Under acidic condition CANA was stable and MET was degraded up to $1.3 \%$. Under basic stress CANA was degraded up to $1.7 \%$ and MET was degraded up to $3.2 \%$. Under oxidative stress
Canagliflozin was degraded up to $6.4 \%$ and MET was degraded up to 2\%. Under thermal stress studies, CANA was degraded up to 4.8\% and MET was found to be stable. Under photolytic stress CANA and MET both were stable. From these stress studies it is thus concluded that CANA was not stable in basic, peroxide and thermal conditions whereas MET was unstable in basic condition. The developed method effectively separated the degradation products or impurities. Therefore, the developed method is considered to be highly specific and selective for intended use. 

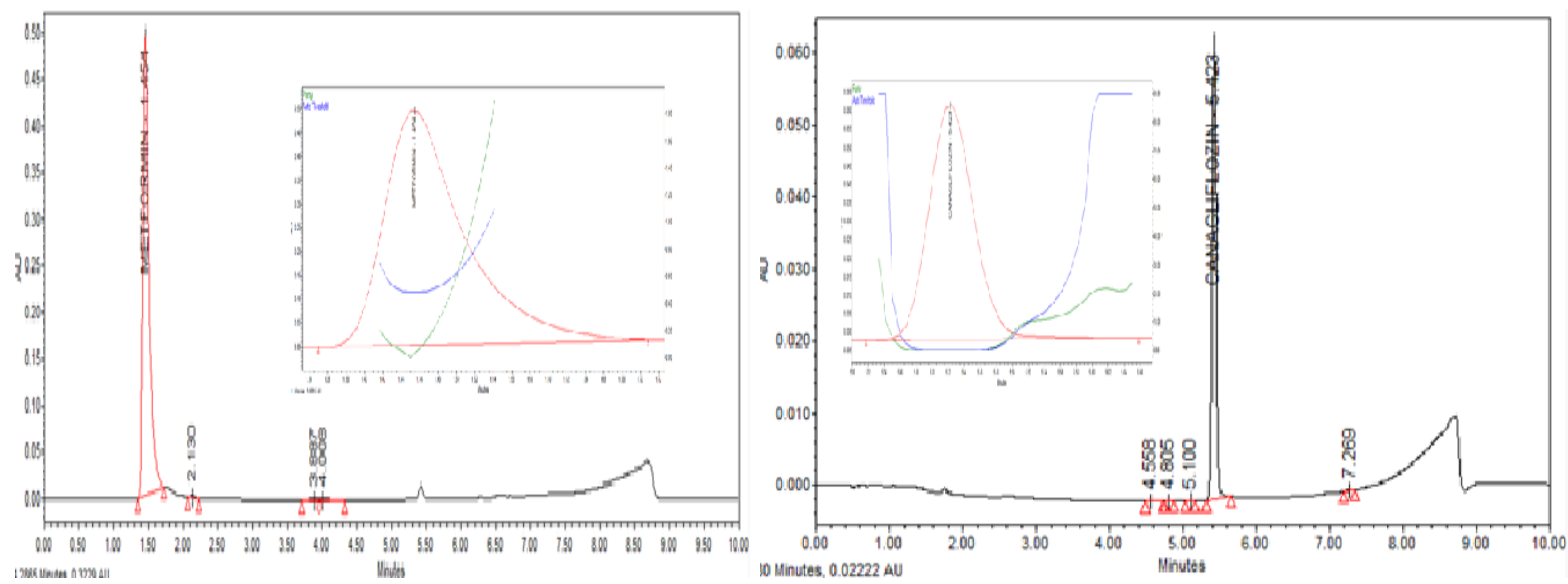

Fig. 5 Chromatograms of CANA and MET under acid stress
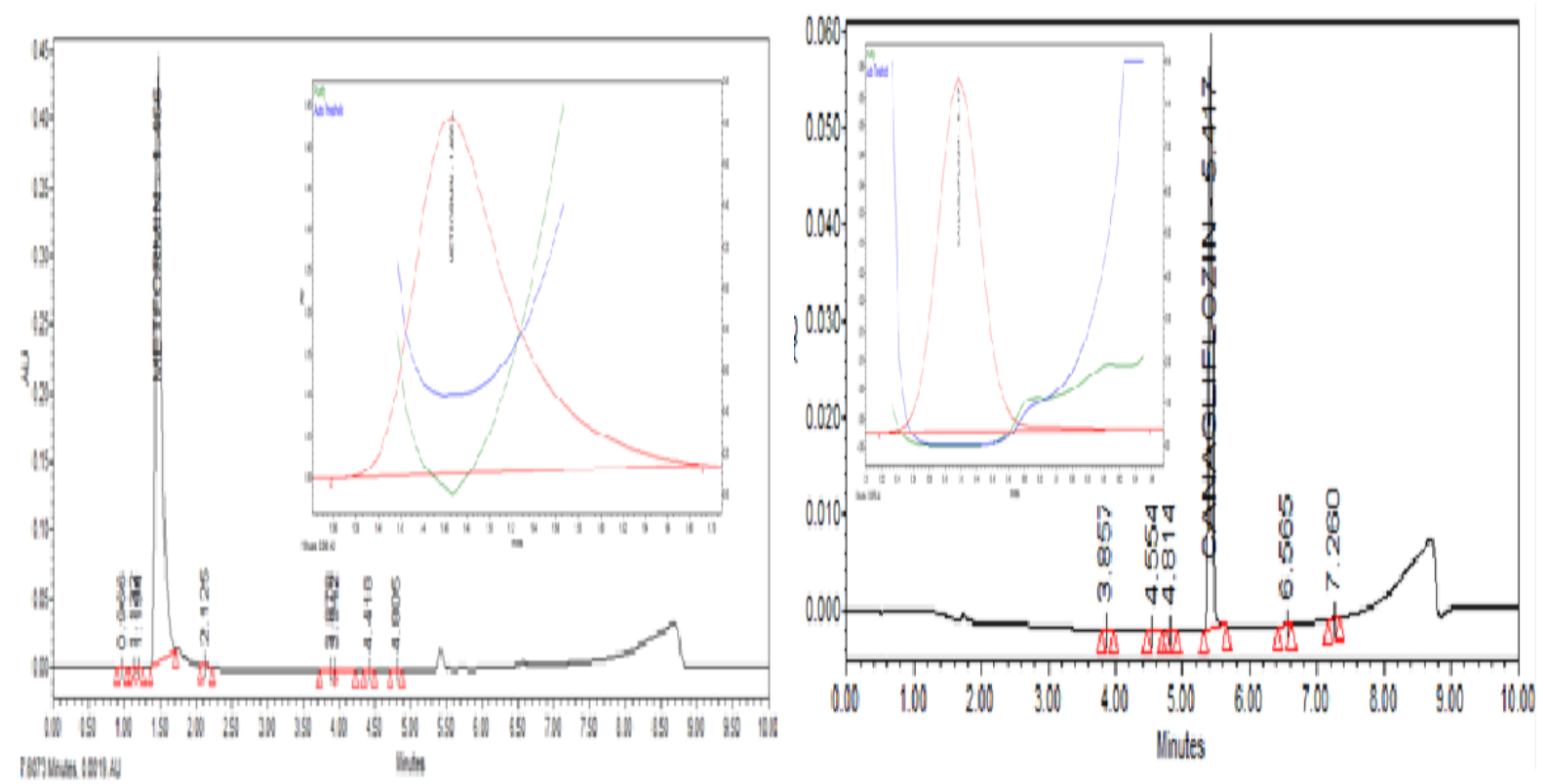

Fig. 6 Chromatograms of CANA and MET under basic stress
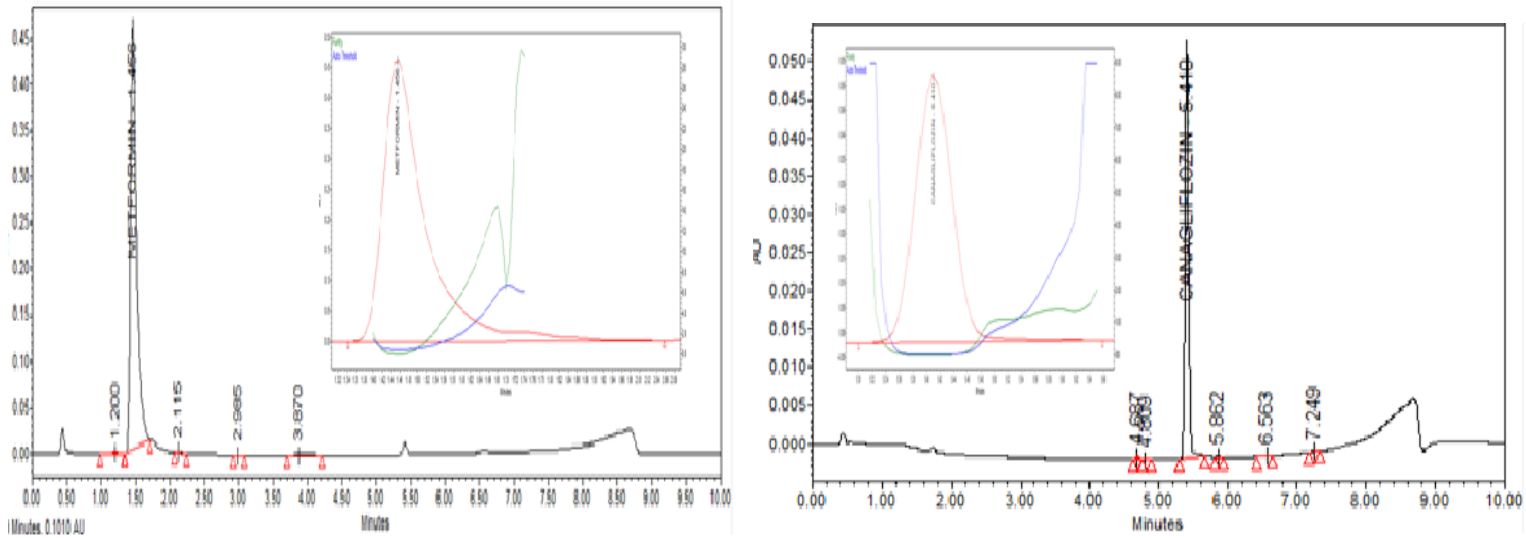

Fig. 7 Chromatograms of CANA and MET under peroxide stress 

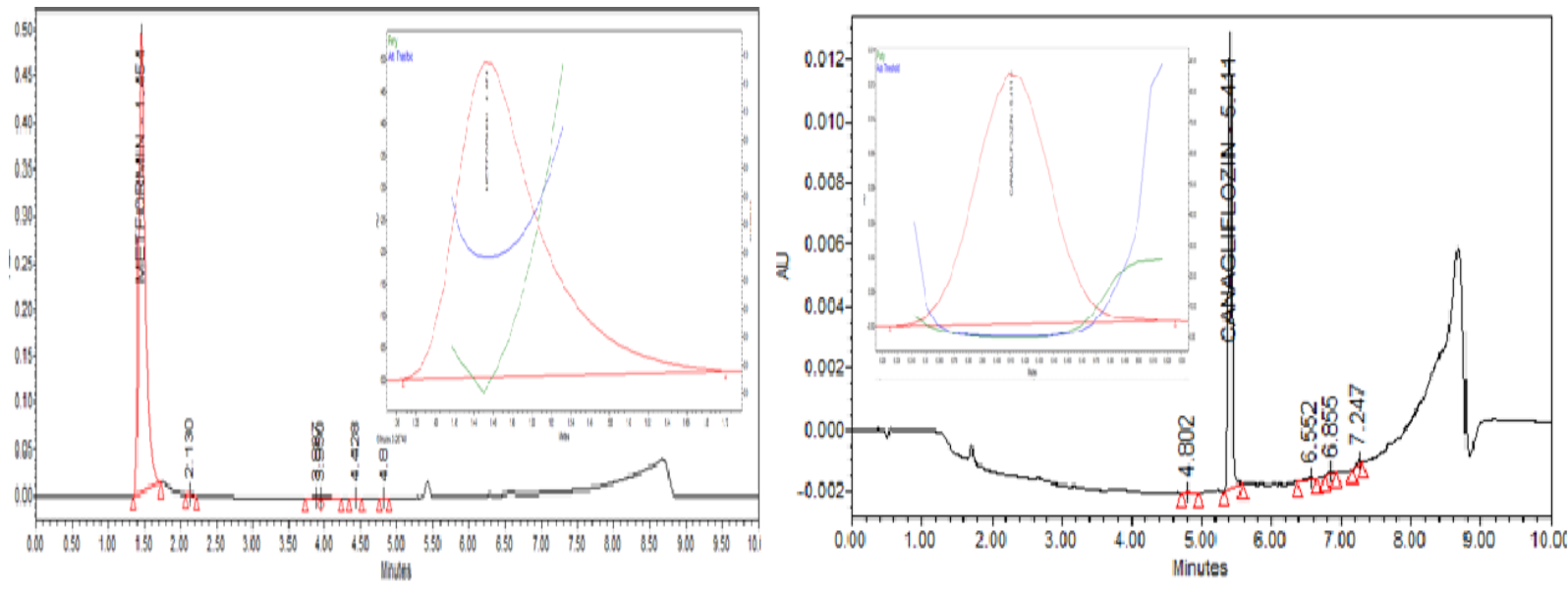

Fig. 8 Chromatograms of CANA and MET under thermal stress
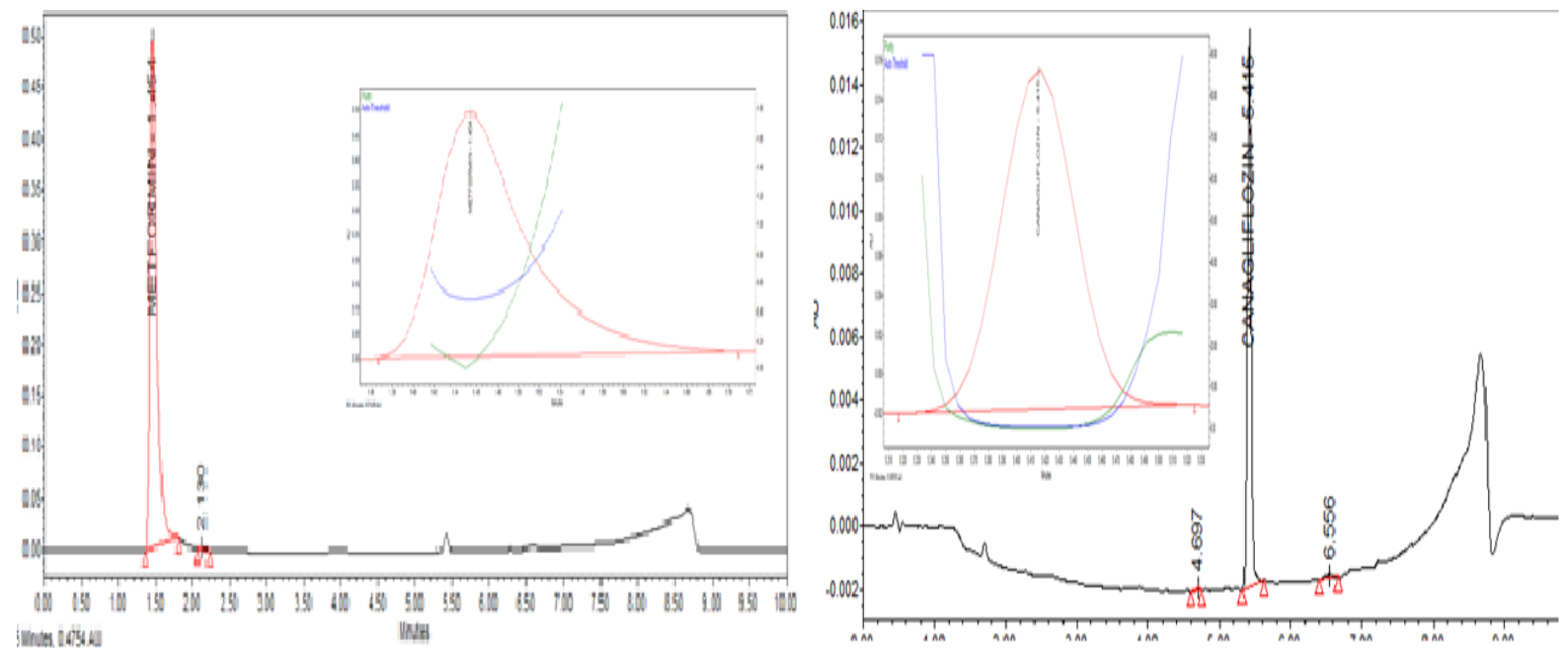

Fig. 9 Chromatograms of CANA and MET under photolytic stress

\section{CONCLUSION}

The novel, simultaneous stability indicating method developed for quantitative analysis of CANA and MET in fixed dose pharmaceutical dosage form. The developed method was validated by testing its linearity, accuracy, precision, specificity, limits of detection and quantification. The shorter run time enables rapid determination of the drugs individually or in combination in in-process testing and finished product testing. The method was found to be specific and stability indicating. This method exhibited an excellent performance in terms of sensitivity and speed hence method can be applicable for dissolution studies for finished dosage forms. The method is more economical and suitable for laboratory use as solvent consumption is very less. Conventional reported HPLC methods may be replaced by the proposed UPLC method because of its superiority. 


\section{REFERENCES}

1. Oneil MJ., Smith A., Heckelman PE., The Merck Index: 2001, 13: pp. 349.

2. R.S.Satoskar., S.D.Bhandarkar and S. S. Ainapure., "Pharmacology and Pharmacotherapeutics", Popular Prakashan: $2001,13^{\text {th }}$ edition, Mumbai, India.

3. C.J.Bailey, M.R.C. Path., R.C.Turner. Metformin NewEngand Journalof medicinal chemistry, 1996, 334: 574579.

4. Burger's Medicinal Chemistry and drug discovery, Wiley Interscience: 2007, New Jersey (6 th edition).

5. Edward Chao, C., Drugs of the Future, 2011, 36:351-357.

6. Hitt E., Uses of metformin may extend beyond patients with type 2 diabetes. Drugs. 1995, 63:1879-94.

7. Madukar A., Prince.A., Vijay kumar R., Sanjeeva Y., Jagadeeshwar .K., D. Raghupratap., Simple and sensitive analytical method development and validation of metformin hydrochloride by RP-HPLC. International Journal of Pharmacy and Pharmaceutical Sciences. 2011, 3(3):117-120.

8. Cijo M Xavier., Kanakapura Basavaiah., RP-UPLC development and validation of metformin hydrochloride in pure drug and pharmaceutical formulations. World journal of pharmacy and pharmaceutical sciences. 2015, 4(4): 1649-1668.

9. Maddu Suma., K.Manasa., Ch.Rajakumari., and B. Lakshmaiah., RP-HPLC method development and validation for the estimation of canagliflozin in tablet dosage form. International Journal of Pharmacy. 2014, 5(4):1288-1292.

10. Ishpreet Kaur., Sharad Wakode., Harsharan Pal Singh., Satish Manchand., Development and Validation of a Stability-Indicating Reverse Phase HPLC-PDA Method for Determination of Canagliflozin in Bulk and Pharmaceutical Dosage Forms. Pharmaceutical methods. 2016, 7(1):54-62.

11. Uttam Prasad Panigrahy., Sunil Kumar Reddy., A novel validated RP-HPLCDAD method for the simultaneous estimation of metformin hydrochloride and canagliflozin in bulk and pharamaceutical tablet dosage form with forced degradation studies. International research journal of pure \& Applied chemistry. 2015, 31(3): 1489-1507.

12. Nareddy Preethi Reddy.,Naga Thirumalesh Chevela., A validated 
stability indicating RP-HPLC method for simultaneous determination of metformin and canagliflozin in pharmaceutical formulation. World journal of pharmacy and pharmaceutical sciences. 2015, 4(12): 631-640.

13. PS Reddy, S Sait, KK Hotha., Estimation of Naproxen Related substances in Sumatriptin Succcinate and Naproxen Sodium Tablets by UPLC, Asian journal of Chemistry. 25(17): 9717-9721.

14. ICH - Q2 (R1), (2005). Guideline on Validation of Analytical Procedure: Text and Methodology.
15. Vijay Kumar. R , Vinay U Rao A., Novel, Rapid, and Validated StabilityIndicating UPLC Method for the Estimation of Drotaverine Hydrochloride and Ibuprofen Impurities in Oral Solid Dosage Form. Scientia Pharmceutica. 2015; 83:567581

16. ICH - Q1A (R2), Stability Testing of New Drug Substances and Products, 2003.

17. ICH - Q1B, Photo Stability Testing of New Drug Substances and Products, 1996.

How to cite this article:

Vijay Kumar et al., A Novel Simultaneous Stability-Indicating UPLC Assay Method for Metformin Hydrochloride and Canagliflozin in Oral Solid Dosage Form. Int. J. Adv. Pharm. Biotech., 2018; 4(1): 10-22. 